\title{
Impact of organisational factors on tacit knowledge sharing in HEIs: Focusing the mediating role of KM system quality
}

\author{
Haleema Hassan ${ }^{\mathbf{a}^{*}}$
}

${ }^{a}$ Graduate School of Business, SEGi University, Kota Damansara, Malaysia

\begin{tabular}{l}
\hline C H R O N I C L E \\
\hline Article history: \\
Received: September 18, 2020 \\
Received in revised format: \\
November 182020 \\
Accepted: December 12, 2020 \\
Available online: \\
December 12, 2020 \\
\hline Keywords: \\
Organisational factors \\
KM system quality \\
Tacit knowledge sharing \\
\end{tabular}

\section{A B S T R A C T}

Higher Education Institutions (HEIs) greatly relies on tacit knowledge sharing. Hence, it is important to investigate the means of promoting knowledge retention. The growth of technology in knowledge management system triggers the transformation of knowledge quality to leverage institutional knowledge. HEIs as knowledge provider needs a knowledge sharing network which can meet the demands of changing knowledge. This paper aims to study the mediating role of knowledge management (KM) system quality between organizational factors and tacit knowledge sharing among academics of HEIs. Barron and Kenny method was used to measure the direct and indirect influence of KM system quality between organisational factors and tacit knowledge sharing. The prelude findings reveal that knowledge management system was effective through organisational factors which promote tacit knowledge sharing among academics of HEIs.

\section{Introduction}

According to Kakabadse et al. (2003), knowledge is known as the centre of global economy transformation. As knowledge intensive organisations, Higher Education Institutions (HEIs) are most suitable places to practice knowledge sharing activities and specialize in research as well as synthesis and transmission of knowledge (Altbach, 2015). Dhamdhere (2015) stated that human effort is the main source of generating knowledge in the academic context, and it can be developed through educational and research activities, innovation, and learning. It is important that the knowledge created, stored, and shared by each agent can contribute to the efficiency of the entire system for the success in HEIs (Rowley, 2000). According to Kidwell et al. (2000), since knowledge sharing is the "raison d'être" of HEIs, they need to promote knowledge creativity and gain competitive excellence. Yet, the exchange of knowledge and expertise with colleagues enhance job performance. Knowledge has been categorized into tacit and explicit forms. To succeed in the real world tasks, much of the knowledge is tacit (Sternberg \& Horvath, 1999). It is difficult to transfer tacit knowledge because it is placed in the minds of employees (Chugh, 2018), yet important to share to sustain innovation. As, the increased demand of global standards, HEIs are urged to train more knowledgeable students. Where tacit knowledge sharing is an underlying source to create new knowledge and capabilities. Furthermore, tacit knowledge sharing is assisted by technology. Employees in higher learning organisations, involving effective KM system, are better able to have access to quality knowledge. In order to sustain the intellectual capital of academics, institutions would require to invest on knowledge management system.

\footnotetext{
* Corresponding author. Tel.: +60 1121106391

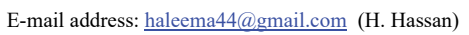


There have been many studies which elaborated on the direct relationship of KM system quality to KM evolution (Lin, 2011) and knowledge sharing (Yasir \& Majid, 2017). There are limited studies on indirect effect of KM system quality to knowledge sharing, specifically within higher learning institutions. The void gape we need to find out the mediating effect of KM system quality between organisational factors and tacit knowledge sharing. To the best of researcher, this is one of first empirical studies among academics of HEIs in context of an emerging economy like Pakistan. To achieve the object, the study aims to examine indirect influence of KM system quality between organisational factors and tacit knowledge sharing.

\section{Hypothesis developments}

\subsection{Tacit knowledge sharing}

Since tacit knowledge is abstract, it is difficult but important to capture and transfer. It is an important and unavoidable issue for every organisation in processing, sharing, and using tacit knowledge (Yu \& Zhou, 2015). Zhang and Han (2008) have termed that transferring the teacher's tacit knowledge is one of the difficult tasks in the universities' knowledge management process. If the knowledge residing inside member's heads has not been shared across the institution, advantage will not be achieved. Hence, universities must convert tacit knowledge into explicit (Chugh, 2018).

\subsection{Knowledge management system quality $K M S Q$}

Due to the height of requirements for knowledge standards, HEIs need to enhance knowledge quality and knowledge sharing activities with employing effective KM system in order to accomplish the needs to develop the skill set and sustain competitiveness. The technology has an important role in encouraging the transfer of tacit knowledge (Chugh, 2018). In HEIs with effective KM system, academics could better search and use quality knowledge to perform knowledge sharing activities.

\subsection{Effective leadership}

The factor, leadership, has an important role to affect the cognitive state of individuals, share knowledge with others, or contribute to the KM system. Elbeltagi (2013) explained transformational leaders promote the tacit and explicit knowledge transfer among employees. The academics would contribute to share more knowledge if their efforts are equally recognized by the institutional leaders. Members of the team can solve problems together and share knowledge with the coaching of empowering leaders (Arnold et al., 2000).

\section{$\mathbf{H}_{1}$ : KM system quality mediates the relationship between effective leadership and tacit knowledge sharing.}

\subsection{Innovation}

Innovation is defined as the ability to combine novel ideas, beliefs, and concepts (Manhart \& Thalmann, 2015). The foundation of organisational survival is innovation (Han et al., 1999; Hurley \& Hult, 1998). The increased demand of innovative educational services urges academics to engage more for knowledge exchange purposes. The main body of organisational knowledge is tacit knowledge, which is considered important to form the innovation capabilities of individuals and organisations (Liu \& Cui, 2012).

\section{$\mathbf{H}_{2}$ : KM system quality mediates the relationship between innovation and tacit knowledge sharing.}

\section{5: Organisational structure}

The effectiveness of knowledge implementation depends on organisational structure (Enayati \& Ghasabeh, 2012) in promoting information sharing. Organisations are forced by a knowledge-based economy to adopt organisational structure for the proper application of knowledge and management resources (Gelard et al., 2013). Structure which is more integrated, less formalised, and less centralised can ease information sharing with other members in the development of knowledge sharing (Mahmoudsalehi et al., 2012).

\section{H3: KM system quality mediates the relationship between organisational structure and tacit knowledge sharing.}

\section{6: Organisational reward}

The regularity of knowledge sharing is positively linked to organisational rewards and incentives, such as bonuses and promotions. Many organisations adopted the reward systems to guarantee the behaviour of proper knowledge sharing (Šajeva, 2014). Bock et al. (2005) found that extrinsic rewards such as organisational incentives had positively affected the intention of knowledge sharing. Cabrera et al., (2006) and Kukarni et al., (2006) argued that employees with a higher incentive are likely to share and utilize knowledge and consider KMS as advantageous.

$\mathbf{H}_{4}$ : KM system quality mediates the effect of organisational reward on tacit knowledge sharing. 


\section{Materials and Models}

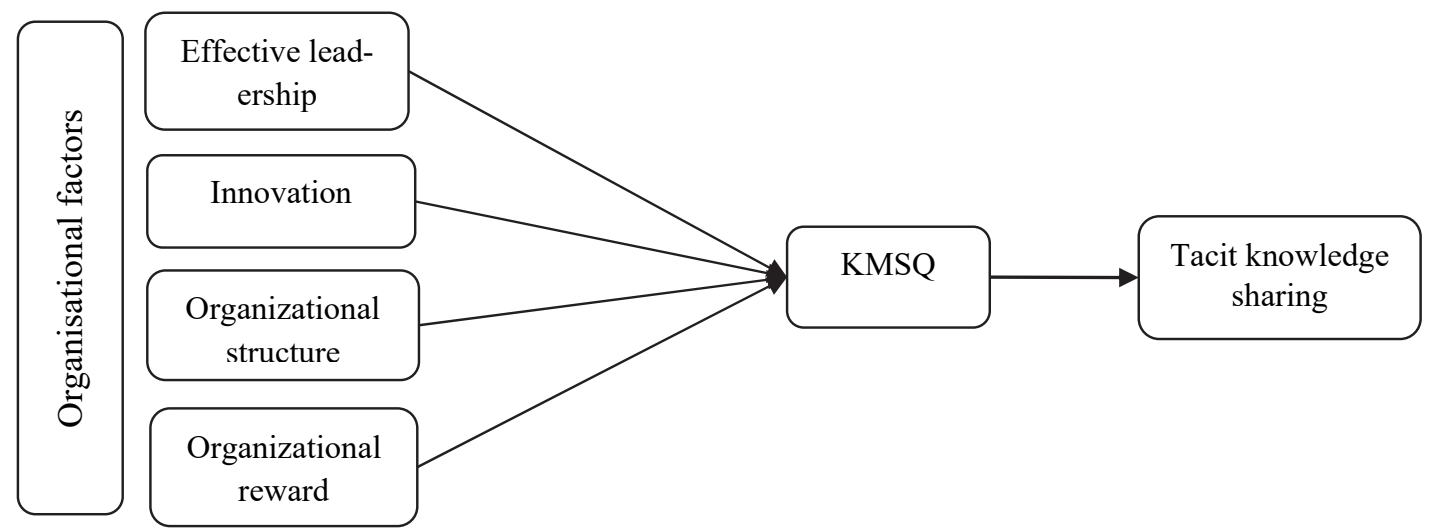

Fig. 1. Model of the study

\subsection{Materials}

Data was collected from the academics of 22 universities both public and private funded located in Islamabad city of Pakistan. Disciplines that replied included institutions of arts, law, business, IT, economics and others. A total of 500 questionnaires were distributed and obtained 344 valid surveys with a return rate of $68.8 \%$. Demographic data for respondents in this study is shown in Table 1.

Table 1

Respondents' demographic statistics

\begin{tabular}{|c|c|c|c|}
\hline Variable & Category & $\mathrm{n}$ & $\%$ \\
\hline \multirow[t]{3}{*}{ Gender } & Male & 261 & 75.9 \\
\hline & Female & 83 & 24.1 \\
\hline & Total & 344 & 100 \\
\hline \multirow[t]{5}{*}{ Age } & 21-30 years & 160 & 46.5 \\
\hline & $31-40$ years & 91 & 26.5 \\
\hline & $41-50$ years & 73 & 21.2 \\
\hline & $51-60$ years & 20 & 5.8 \\
\hline & Total & 344 & 100 \\
\hline \multirow[t]{4}{*}{ Education } & Masters & 198 & 57.56 \\
\hline & $\mathrm{PhD} /$ Doctorate & 128 & 37.21 \\
\hline & Post Doc & 18 & 5.23 \\
\hline & Total & 344 & 100 \\
\hline \multirow[t]{6}{*}{ Experience } & $1-5$ years & 125 & 36.3 \\
\hline & $6-10$ years & 76 & 22.1 \\
\hline & $11-15$ years & 66 & 19.2 \\
\hline & $16-20$ years & 41 & 11.9 \\
\hline & More than 20 years & 36 & 10.5 \\
\hline & Total & 344 & 100 \\
\hline
\end{tabular}

\section{Data analysis}

The data was collected through self-administered online survey. To measure the organisational factors 5point Likert scale has been used. The constructs' generalizability and validity have been observed by many researchers. For the purpose to measure organisational factors total of 17 items were measured. Effective leadership was measured using 4 items developed by Riege (2005), 3 items of innovation was adapted from Bock et al (2005), 6 items of organisational structure developed by Chen \& Huang (2007), 4 items of organisational reward adapted from Lin (2007d) were used.

KM system quality was further measured using the 5 items developed by Lin (2011) and DeLone \& McLean (2003). The dependent variable, tacit knowledge sharing, was determined using 5 items by Bock and Kim (2002). Table 2 represents the Cronbach's values for each variable. 
Table 2

Reliability statistics

\begin{tabular}{|c|c|c|c|c|c|c|}
\hline Construct & Item & $\mathrm{FL}$ & AVE & Cronbach's $\alpha$ & Mean & $\mathrm{SD}$ \\
\hline \multirow[t]{4}{*}{ Effective leadership } & EF1 & 0.817 & 0.653 & 0.80 & 4.33 & 1.65 \\
\hline & EF2 & 0.861 & & & 3.87 & 1.64 \\
\hline & EF3 & 0.704 & & & 4.66 & 1.60 \\
\hline & EF4 & 0.781 & & & 4.79 & 1.62 \\
\hline \multirow[t]{3}{*}{ Innovation } & INN1 & 0.696 & 0.765 & 0.881 & 4.96 & 1.65 \\
\hline & INN2 & 0.751 & & & 3.87 & 1.64 \\
\hline & INN3 & 0.741 & & & 4.60 & 1.67 \\
\hline \multirow[t]{6}{*}{ Organisational structure } & OS1 & 0.867 & 0.644 & 0.752 & 4.74 & 1.73 \\
\hline & OS2 & 0.877 & & & 4.20 & 1.69 \\
\hline & OS3 & 0.774 & & & 4.07 & 1.78 \\
\hline & OS4 & 0.736 & & & 4.31 & 1.77 \\
\hline & OS5 & 0.769 & & & 4.79 & 1.73 \\
\hline & OS6 & 0.821 & & & 4.87 & 1.91 \\
\hline \multirow[t]{4}{*}{ Organisational reward } & OR1 & 0.779 & 0.741 & 0.851 & 4.74 & 1.76 \\
\hline & OR2 & 0.748 & & & 4.97 & 1.53 \\
\hline & OR3 & 0.834 & & & 4.60 & 1.84 \\
\hline & OR4 & 0.672 & & & 4.76 & 1.63 \\
\hline \multirow[t]{5}{*}{ KM system quality } & KMSQ1 & 0.767 & 0.698 & 0.790 & 4.95 & 1.67 \\
\hline & KMSQ2 & 0.719 & & & 4.76 & 1.59 \\
\hline & KMSQ3 & 0.781 & & & 4.90 & 1.57 \\
\hline & KMSQ4 & 0.792 & & & 4.42 & 1.71 \\
\hline & KMSQ5 & 0.774 & & & 4.53 & 1.63 \\
\hline \multirow[t]{5}{*}{ Tacit knowledge sharing } & TKS1 & 0.868 & 0.769 & 0.890 & 4.92 & 1.66 \\
\hline & TKS2 & 0.892 & & & 4.59 & 1.81 \\
\hline & TKS3 & 0.878 & & & 3.75 & 1.90 \\
\hline & TKS4 & 0.861 & & & 4.64 & 1.72 \\
\hline & TKS5 & 0.866 & & & 4.81 & 1.67 \\
\hline
\end{tabular}

At first, descriptive statistics and correlations were used to analyse the data, furthermore, the mediation effect was studied using causal stage method (Baron \& Kenny) and (PROCESS Macro, Preacher \& Hayes, 2008). For the purpose to evaluate the model fitness, Confirmatory factor analysis (CFA) was used. This study used square root mean square error of approximation (RMSEA) and comparative fit index (CFI) to calculate the construct validity and overall model fit goodness of fit index (GFI). The threshold value for CFI and GFI stated by Hu \& Bentler (1999) is 0.90 or higher while Brown \& Cudeck (1993) recommended value for RMSEA is 0.05 or less. Table 3 shows the CFI, GFI and RMSEA scores.

Table 3

Correlations coefficient

\begin{tabular}{|c|c|c|c|c|c|c|c|c|c|}
\hline & & Mean & SD & 1 & 2 & 3 & 4 & 5 & 6 \\
\hline 1 & Effective leadership & 3.64 & 0.83 & 1 & & & & & \\
\hline 2 & Innovation & 3.58 & 0.91 & $0.28 * *$ & 1 & & & & \\
\hline 3 & Organisational structure & 3.57 & 0.68 & $0.22 *$ & 0.15 & 1 & & & \\
\hline 4 & Organisational reward & 3.78 & 0.89 & $0.20 *$ & 0.09 & $0.17 *$ & 1 & & \\
\hline 5 & KM system quality & 3.67 & 0.85 & $0.51 * *$ & $0.38 * *$ & $0.41 * *$ & $0.38 * *$ & 1 & \\
\hline 6 & Tacit knowledge sharing & 3.88 & 0.90 & $0.34 * *$ & $0.34 * *$ & $0.564 * *$ & $0.24 *$ & $0.48 * *$ & 1 \\
\hline
\end{tabular}

\section{1: Baron \& Kenny method}

The current study used Baron and Kenny (1986) method to study the mediation effect of KM system quality between organisational factors and tacit knowledge sharing. In order to validate the four conditions of mediation defined by Barron \& Kenny (1986), simple regressions were used.

Table 4

Simple regression

\begin{tabular}{|c|c|c|c|c|c|c|c|c|c|c|}
\hline \multirow[b]{2}{*}{ Independent variables } & \multicolumn{5}{|c|}{ KM system quality } & \multicolumn{5}{|c|}{ TKS } \\
\hline & $\beta$ & t-value & $\mathrm{R}^{2}$ & SE & Sig. & $\beta$ & t-value & $\mathrm{R}^{2}$ & SE & Sig. \\
\hline Effective leadership & 0.51 & 8.76 & 0.37 & 0.07 & 0.00 & 0.45 & 6.23 & 0.17 & 0.13 & 0.00 \\
\hline Innovation & 0.47 & 7.10 & 0.26 & 0.05 & 0.00 & 0.31 & 5.78 & 0.32 & 0.07 & 0.00 \\
\hline Organisational reward & 0.53 & 7.19 & 0.19 & 0.04 & 0.00 & 0.51 & 9.37 & 0.11 & 0.09 & 0.00 \\
\hline Organisational structure & 0.50 & 5.66 & 0.15 & 0.06 & 0.00 & 0.24 & 6.68 & 0.06 & 0.08 & 0.00 \\
\hline KM system quality (mediator) & & & & & & 0.54 & 8.87 & 0.34 & 0.07 & 0.00 \\
\hline
\end{tabular}


Table 4 presents the simple regression values, signifying that effective leadership $(\beta=0.51, t=8.76, p<0.00)$ is positively and directly associated with KM system quality. Which satisfied first condition. While second condition of mediation was also met as effective leadership is significantly associated with (TKS) tacit knowledge sharing $(\beta=0.45, \mathrm{t}=6.23, \mathrm{p}<0.00)$. Of the third criterion, KM system quality also positively and directly related to (TKS) tacit knowledge sharing $(\beta=0.54$, $\mathrm{t}=8.87$, $\mathrm{p}<0.00$ ). The fourth criterion states that the presence of a mediator can make the direct relationship of independent variable and dependent variable to become insignificant. This condition was checked evaluating the multiple regression values. Thus, Table 4 shows that effective leadership is insignificantly $(\beta=0.26, \mathrm{t}=2.04)$ related to tacit knowledge sharing. The procedure was repeatedly followed for the rest of hypothesis. Of the first criterion was fulfilled as table 4 shows that innovation shared positive and direct relationship to KM system quality $(\beta=0.47, \mathrm{t}=7.10, \mathrm{p}<0.00)$. Meeting the second criterion, innovation also proved to share direct and positive relationship with (TKS) tacit knowledge sharing $(\beta=0.31, t=5.78, p<0.00)$. Whereas, satisfying the third condition KM system quality had direct and positive association to (TKS) tacit knowledge sharing $(\beta=$ $0.54, \mathrm{t}=8.87, \mathrm{p}<0.00)$. For the fourth condition, multiple regression table shows that innovation shared insignificant relationship with tacit knowledge sharing when KM system quality was added as mediator $(\beta=0.36, \mathrm{t}=2.64)$.

To further evaluate the mediation effect of KM system quality between organisational reward and (TKS) tacit knowledge sharing Table 4 proves that organisational reward is positively and directly associated to KM system quality $(\beta=0.53, \mathrm{t}=7.19$, $\mathrm{p}<0.00)$. Which proved the first condition for mediation. Organisational reward also shared direct and positive association to (TKS) tacit knowledge sharing $(\beta=0.51, \mathrm{t}=9.37, \mathrm{p}<0.00)$. Of the third condition, KM system quality shared direct and positive relationship to (TKS) tacit knowledge sharing $(\beta=0.54, \mathrm{t}=8.87, \mathrm{p}<0.00)$. All the three conditions were met by calculating the simple regression values. Table 5 indicates that organisational reward shared partial mediation. Indicating that relationship between organisational reward and (TKS) tacit knowledge sharing becomes significant but reduced $(\beta=0.36, \mathrm{t}=6.66)$ with inclusion of mediator. KM system quality partially mediates between organisational reward and (TKS) tacit knowledge sharing.

Table 5

Multiple regression

\begin{tabular}{lcccccc} 
Variable & \multirow{2}{*}{$\mathrm{R}^{2}$} & $\mathrm{~F}$ & $\beta$ & t-value & SE & Sig. \\
\hline 1. Effective leadership & 0.47 & 52.22 & 0.26 & 2.04 & 0.07 & 0.07 \\
2. KM system quality & & & 0.52 & 6.89 & 0.06 & 0.00 \\
3. Innovation & 0.41 & 47.03 & 0.36 & 2.64 & 0.08 & 0.05 \\
4. KM system quality & & & 0.54 & 7.33 & 0.05 & 0.00 \\
5. Organisational reward & 0.32 & \multirow{2}{*}{86.44} & 0.36 & 6.66 & 0.08 & 0.00 \\
6. KM system quality & & & 0.25 & 5.74 & 0.07 & 0.00 \\
7. Organisational structure & 0.39 & 51.06 & 0.06 & 0.65 & 0.13 & 0.65 \\
8. KM system quality & & & 0.43 & 8.23 & 0.06 & 0.00 \\
\hline
\end{tabular}

The results in Table 4 further shows that $\mathrm{H} 4$ met the first condition of mediation as organisational structure shared direct and positive relation to $\mathrm{KM}$ system quality $(\beta=0.50, \mathrm{t}=5.66, \mathrm{p}<0.00)$. The second criterion was met as organisational structure was positively and directly associated to tacit knowledge sharing $(\beta=0.24, \mathrm{t}=6.68, \mathrm{p}<0.00)$. Direct and positive relationship of $\mathrm{KM}$ system quality to (TKM) tacit knowledge sharing was also meant to support the mediation conditions $(\beta=0.54, t=8.87, p<0.00)$. Based on the results of multiple regression, the insignificance relationship between organisational structure and (TKM) tacit knowledge sharing $(\beta=0.06, \mathrm{t}=0.65)$ proved that with the inclusion of $\mathrm{KM}$ system quality it effectively mediates.

\section{Discussion}

The study endeavoured to assess the intervening role of KM system quality between organisational factors and tacit knowledge sharing. The findings revealed that effective KM system is crucial for HEIs for easy and quality accessibility to knowledge. The empirical findings of KM system quality as a mediator between effective leadership and tacit knowledge sharing demonstrated that management of HEIs can influence to ensure the deployment of an effective KM system to facilitate tacit knowledge sharing activities among academics. Which will enhance the exchange of quality knowledge among academics and top management. The usage of technology provides better mechanism to process, deliver and exchange quality knowledge as well as to interact well among academics and top management. These findings are in line with Yasir and Majid (2017).

Studies indicate (e.g. Alam et al., 2009; Sandhawalia \& Dalcher, 2008; Kulkarni et al., 2006) that effective KM system infrastructure encourage knowledge management practices beyond the formal lines. The institutions with high quality KM system tend to be more innovative. In other words, easy approach to knowledge repositories enhance more knowledge communications among academics result to excel their tacit knowledge while being more innovative. Innovators and facilitators can provide a conducive environment for knowledge sharing among workers (Kurdi, 2017). Institutional leaders therefore, encourage the networking that support the transfer of tacit knowledge through mentoring and practice so that experts can be found. The next hypothesis was to study the intervening role of KM system quality between organisational structure and tacit knowledge sharing. The findings demonstrated that organisational structure supportive to the usage of tools and technology can, therefore, encourage academics to externalise their knowledge. It is imperative to consider the structure of an organisation 
that ensure the access to the effective information technology. In perspective with the indirect outcomes of KM system quality between organisational reward and tacit knowledge sharing showed that incentives and reward would not influence the academics' choice of using the technology for tacit knowledge sharing. The open institutional culture is encouraged by HEIs by providing incentives for promoting the incorporation of individual skills and experiences into institutional knowledge; knowledge utilisation has many advantages, both in formal and informal aspects and it is noted that KM activities are not only supported by technology (Nair \& Munusami, 2019). However, in relation to the direct influence of KM system quality the findings revealed that support of information technology provides better mechanism for the exchange of valuable information among academics.

\section{Research contributions and implications}

This study presents an in-depth analysis of organisational factors and tacit knowledge sharing, as well as the mediating role of KM system quality. The result of this study may encourage the HEIs' leadership to create an institutional environment that can flourish innovative ideas. Since HEIs are based on knowledge business, a supportive culture to new knowledge capturing and thus sharing can, therefore, elevate the knowledge assets of the organizations.

According to Nair and Munusami (2019) tacit knowledge sharing requires a culture conducive to share it. The study also added some empirical investigation of the KM system quality as mediator between organisational factors and tacit knowledge sharing in countries, like Pakistan which is a knowledge emerging economy.

HEIs need a leadership behaviour that can facilitate a climate of knowledge creation and sharing among employees. Consequently, to provide a climate conducive to innovative research. In addition, institutional management should focus on building a supportive organisational structure to socializing which can ultimately promote knowledge exchange. The result drawn from the analysis of mediation effect of KM system quality between organisational factors (effective leadership, innovation, organisational structure) and tacit knowledge suggested that technology support leads to promote tacit knowledge sharing. For the purpose, to encourage academics for the tacit knowledge sharing, HEIs leadership should consider the organisational structure that support the innovative climate. Rewarding such knowledge sharing behaviour would further promote and enhance the knowledge activities.

\section{Limitations and directions for future research}

The study deals with some limitations. As current study used online survey method to collect data, due to the response bias future researchers could explore longitudinal method to further validate the findings. Second, the study aimed to identify the effect of organisational factors on tacit knowledge sharing among academics, specifically in the HEIs sector. Future studies can investigate the effect of individual and technological factors on tacit knowledge sharing behaviour of technical, nontechnical, and administrative employees in the institution. Furthermore, any future research would offer greater understanding on the issues if applied on different types of organisations.

\section{References}

Alam, S., Abdullah, Z., Ishak, N., \& Zain, Z. (2009). Assessing knowledge sharing behaviour among employees in SMEs: An empirical study. International Business Research, 2(2), 115-122.

Altbach, P. (2015). Knowledge and education as international commodities. International Higher Education, 28(1-4), Retreived from https://ejournals.bc.edu/ojs/index.

Arnold, J. A., Arad, S., Rhoades, J. A., \& Drasgow, F. (2000). The empowering leadership questionnaire: the construction and validation of a new scale for measuring leader behaviours. Journal of Organisational Behavior, 21(3), $249-269$.

Baron, R. M., \& Kenny, D. A. (1986). The moderator-mediator variable distinction in social psychological research: Conceptual, strategic, and statistical considerations. Journal of Personality and Social Psychology, 51(6), 1173.-1182.

Bock, G., Lee, J., \& Zmud, R. (2005). Behavioral intention formation in knowledge sharing: Examining the roles of extrinsic motivators, social-psychological forces, and organizational climate. MIS Quarterly, 29(1), 87-111.

Bock, G.-W., \& Kim, Y.-G. (2002). Breaking the myths of rewards: An exploratory study of -. W., and Cudeck, R. (1992), "Alternative ways of assessing model fit", Sociological Methods \& Research, 21(2), 230-258.

Browne, M. W., \& Cudeck, R. (1992). Alternative ways of assessing model fit. Sociological Methods \& Research, 21(2), 230258.

Chen, C. J. \& Hung, S. W. (2007). To give or to receive? Factors influencing members' knowledge-sharing and community promotion in professional virtual communities. Information \& Management, 47(4), 226-236.

Chugh, R. (2018). Tacit Knowledge Transfer in Australian Universities Exploring the Barriers and Enablers : 04054, 1-7.

Delone, W. H., \& McLean, E. R. (2003). The DeLone and McLean model of information systems success: a ten-year update. Journal of Management Information Systems, 19(4), 9-30.

Dhamdhere, S. N. (2015). IMPORTANCE OF KNOWLEDGE MANAGEMENT. (January), 162-183.

Enayati, G., \& Ghasabeh, M. (2012). Studying the effect of organizational culture, organizational structure, and information technology on effectiveness of knowledge management: Using Khorasan Regional Electricity Company as a case study. African Journal of Business Management, 6(24), 7170-7183.

Gelard, P., Hassanabadi, M., \& Rad, M. S. (2013). Looking into Knowledge Management from Organizational Structure 
Perspective. 518-529.

Han, J. K., Kim, N., \& Srivastava, R. K. (1999). Market orientation and organizational performance: is innovation a missing link? Journal of Marketing, 20(9), 837-865.

Hu, L., \& Bentler, P. M. (1999). Cutoff criteria for fit indexes in covariance structure analysis: Conventional criteria versus new alternatives. Structural Equation Modeling, 6(1), 1-55.

Hurley, R. F., \& Hult, G. T. M. (1998). Innovation, market orientation, and organizational learning: an integration and empirical examination. Journal of Marketing, 62(3), 42-54.

Kakabadse, N., Kakabadse, A., \& Kouzmin, A. (2003). Reviewing the Knowledge Management Literature: Towards a Taxonomy. Journal of Knowledg Management, 7(4), 75-91.

Kulkarni, U. R., Ravindran, S., \& Freeze, R. (2006). A knowledge management success model: Theoretical development and empirical validation. Journal of Management Information Systems, 23(3), 309-347.

Kurdi, O. F. A. (2017). Knowledge-Sharing Management in the ContextHigher Education Institutions. Brunel University London, Brunel Business School.

Liao, S. H., Fei, W. C., \& Chen, C. C. (2007). Knowledge sharing, absorptive capacity, and innovation capability: an emperical study of Taiwan's knowledge intensive industries. Journal of Information Science, 33(3), 340-359.

Lin, C. (2007). To share or not to share: Modeling Tacit Knowledge Sharing, It's Mediator and Antecedents, 411-412. Systems, 23(3), 309-347.

Lin, H. F. (2011). Antecedents of the stage-based knowledge management evolution. Journal of Knowledge Management. 23(3), 309-347.

Liu, Z.-G., \& Cui, J. (2012). Improve Technological Innovation Capability of Enterprises Through Tacit Knowledge Sharing. Procedia Engineering, 2072- 2076. https://doi.org/http://dx.doi.org/10.1016/j.proeng.2012.01. 264

Mahmoudsalehi, M., Moradkhannejad, R., \& Safari, K. (2012). How knowledge management is affected by organizational structure. The Learning Organization, 19(6), 518-528.

Manhart, M., \& Thalmann, S. (2015). Protecting organizational knowledge: A structured literature review. Journal of Knowledge Managment, 19(2), 190-211.

Nair, B. V, \& Munusami, C. (2019). Knowledge management practices An exploratory study at the Malaysian higher education institutions. Journal of Research in Innovative Teaching \& Learning, 13(2).

Preacher, K. J., \& Hayes, A. F. (2004). SPSS and SAS procedures for estimating indirect effects in simple mediation models. Behavior Research Methods, Instruments, \& Computers, 36(4), 717-731.

Preacher, K. J., \& Hayes, A. F. (2008). Asymptotic and resampling strategies for assessing and comparing indirect effects in multiple mediator models. Behavior Research Methods, 40(3), 879-891.

Riege, A. (2005). Three-dozen knowledge sharing barriers manager must consider. Journal of Knowledge Managment, 9(3), 18-35. https://doi.org/10.1108/13673270710728231

Rowley, J. (2000). Is higher education ready for knowledge management? International Journal of Educational Management, 14(7), 325-333.

Šajeva, S. (2014). ScienceDirect Encouraging knowledge sharing among employees : how reward matters. 156(April), 130134. https://doi.org/10.1016/j.sbspro.2014.11.134

Sandhawalia, B., \& Dalcher, D. (2008). Knowledge management capability framework. IFIP 20th World Computer Congress, Conference on Knowledge Management in Action, 165-180.

Sternberg, R. J., \& Horvath, J. A. (1999). Tacit knowledge in professional practice: Researcher and practitioner perspectives. Psychology Press.

Yasir, M., \& Majid, A. (2017). World Journal of Entrepreneurship, Management and Sustainable Development.

Yu, D., \& Zhou, R. (2015). Tacit Knowledge Sharing Modes of University Teachers From the Perspectives of Psychological Risk and Value. International Journal of Higher Education, 4(2), 214-224. https://doi.org/10.5430/ijhe.v4n2p214

Zhang, L., Han, Z. (2008). Analysis on the management of College teachers' tacit knowledge. International Education Studies, 1(3), 21-24. 
(C) 2021 by the authors; licensee Growing Science, Canada. This is an open access article distributed under the terms and conditions of the Creative Commons Attribution (CC-BY) license (http://creativecommons.org/licenses/by/4.0/). 